\title{
A Case For Integrating Technology Into Small Enterprises Development In Nigeria
}

Nkanta Frank Ekanem, (Email: nfekanem@hotmail.com), Howard University

\begin{abstract}
This article presents arguments to support the integration of simple and easily adaptable forms of technology into small and medium-sized enterprises. Empirical evidence with Nigerian data shows that technological orientation leads to efficient production measured in terms of increased output (gross sales), employment and start-up capital. However, research data from other developing economies show that there are many more advantages, which may also apply to Nigeria. These include easy access to the global market made possible by the use of the Internet and web site procurement and advertising.
\end{abstract}

\section{INTRODUCTION}

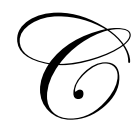

urrent civilian governments in Nigeria, at State and Federal levels rank the policy of poverty eradication at a level that has never been heard of in the history of Nigerian nationhood. Some implementation strategies have been experimented, one time or the other, including cash payments to certain categories of their unemployed populations, especially University graduates. Another strategy is the UNDP supported establishment of Skills Acquisition Centers in many states of the federation. Another policy, which is also being implemented, is providing funding to assist the growth of small and medium-sized enterprises. As part of this policy, banks are encouraged to make loans to "established" enterprises, and to ensure that such funds are properly utilized; banks are encouraged to have equity in these enterprises. A fourth policy is the National Economic Empowerment and Development Strategy (NEEDS) and (SEEDS), the state equivalents to NEEDS, as their development strategies. NEEDS and SEEDS policy encompass a wide range of initiatives which include the fight against corruption and due process in governance, economic liberalization, and other policies aimed at bringing about macro- and microeconomic adjustment to promote efficiency in the national economy.

The important elements of NEEDS and SEEDS policy are as follows; there must be transparency in governance which ensures that all applicable laws are applied without fear or favor in a sustained manner; economic liberalization which allows resources to flow to sectors with maximum potential to yield highest "profit"; and perhaps more than all else, government's sustained budgetary support, dedication and sincerity in the mobilization of essential government machinery to ensure its success. There must also be transparency on the part of businesses, which ensures that all types of government and private assistance are properly accounted for. Given these congenial macro- and micro-economic environments, we believed that micro-enterprises could be used as an instrument for poverty reduction. Because of the proven effectiveness of technology in bringing about increased productivity (Ekanem, 2005), efficiency and cost reduction, this paper is devoted to the discussion of integrating technology into small and medium-sized enterprises development. This strategy represents a small aspect of NEEDS and SEEDS, namely providing funding for small and medium-sized enterprises as a medium of achieving poverty elimination, but instead of asking the banks to "turn away" from their traditional role, the task is left into the hands of independent consultants and professionals at Small Business Development Centers at local Universities to train, monitor and evaluate the performance of business owners and managers and report their findings to funding agencies and governments. 


\section{BACKGROUND}

The background to this paper is my paper titled "A Methodology for Developing and Testing the Effectiveness of Using Entrepreneurial Skills and Supply-Side Innovation to Improve the Performance of Small and Medium-Sized Enterprises" in which I reported the propensity of Nigerian small and medium-sized enterprises to regard financial assistance as the most essential support they wish to get from government or funding agencies. In the survey of 190 small enterprises conducted in 2002, over $62 \%$ of the enterprises ranked financial assistance as their most desired support; over $23 \%$ preferred counseling, monitoring and management assistance, and only $13 \%$ preferred technical assistance.

Among the enterprises surveyed, $33 \%$ would like to use their financial assistance to improve technological capability of the enterprise, while $32 \%$ would like to use it to invest on new plants and equipment to support expansion. Although some Nigerian small and medium-sized enterprises have little or no technological and management orientation, they love to be funded by benevolent government or banking institutions which may call for neither the regular servicing of the line of credit nor the repayment of the capital. This is one of the fundamental structural and cultural deficiencies, which the NEEDS and SEEDS policy seeks to eradicate.

\section{WHAT IS MORE CRITICAL TO SMALL AND MEDIUM-SIZED ENTERPRISES IN NIGERIA: FINANCIAL SUPPORT OR TECHNOLOGICAL SUPPORT?}

The survey data describe above reveals that small and medium-sized enterprises in Nigeria consider financial assistance as the more critical input they could receive from government. There is every indication that government is in agreement with this line of business psychology. However, what is wrong with this psychological mindset is that being generously funded is not directly correlated with knowing how to put such funding to its best use. Our survey data reveals that although $62.6 \%$ of the enterprises surveyed revealed their preference for financial assistance, such enterprises, on the average only reported N430,891 per annum. On the contrary, 23.7\% of them, which opted for counseling, monitoring and management assistance, reported gross sales of about N503,244. These compare with $13.1 \%$, which opted for technical assistance. This cohort of enterprises reported N433,620 in gross sales per annum (Ekanem, 2005).

While management orientation appears to be a much superior development intervention instrument in terms of the gross sales reported, the impact of technology can also be seen in terms of employment growth, and start-up capital when specific types of technology and how they are used are analyzed. Examples of such technological innovations are simple types of technology, which can be easily understood and adaptable to the needs and structure of the industry. The examples include accounting, marketing, supply chain and other forms of technologies (Rustagi, 2001; Kohler, 2002). It is common knowledge that the new corps of Nigerian entrepreneurs is college graduates, and so they can and should be able to make increasing use of web site technologies to publicize their businesses. Online method of procurement is becoming an order of the day worldwide, and Nigerian entrepreneurs should not be left out of this wind of technological change. The role of technology in small enterprises has been widely documented, (Dahlman \& Westphal, 1981; Evans \& Jovanovic, 1989; Bhalla \&James, 1991; Biggs, 1999). These authors suggest that technology should be integrated into traditional economic activities in developing countries.

\section{THEORETICAL CONSIDERATION}

In (Ekanem, 2004), the following model was used to test the effectiveness of using owner-specific and institution-specific instruments to design an entrepreneurial development policy. The model tests revealed that the presence of selected instruments, including technology orientation is more able to promote entrepreneurial development than the absence of such instruments:

$Y_{m}=\log \left(\alpha_{0}\right)+\alpha_{n} \log \left(Z_{n}\right)+\alpha_{j}\left(X_{j a}\right)+\alpha_{h}\left(X_{h a}\right)+\alpha_{k}\left(X_{k a}\right)+\varepsilon$

where $Y_{m}$ is a discrete choice objective variables and outcome of an entrepreneurial development, such as job growth, sales growth, poverty reduction, etc., associated with $Z_{n}$ continuous and $X$ discrete intervention instruments. The 
subscripts $\left({ }_{j}, \mathrm{~h}, \mathrm{k}\right)$ represent the presence of the stipulated orientation, ( that is $\mathrm{X}_{\mathrm{j}}, \mathrm{X}_{\mathrm{h}}, \mathrm{X}_{\mathrm{k}}=1$ ) while $\left({ }_{\mathrm{a}}\right)$ represents the absence of such orientation (that is $X_{a}=1$ ). This paper deals with a truncated version of the (Ekanem, 2004) model because only technological instruments are considered, namely

Ym. $=\log \left(\beta_{0}\right)+\beta_{\mathrm{i}}\left(\mathrm{X}_{\mathrm{ia}}\right)+\beta_{\mathrm{j}}\left(\mathrm{X}_{\mathrm{j}}\right)+\ddot{\mathrm{v}}$

where $\left(X_{i}=1\right)$ represents the presence of technological intervention instruments, $\left(X_{a}=1\right)$ represents the absence thereof, and $\left(X_{j}=1\right)$ represents the existence of ample management and other intervention instruments, compatible with entrepreneurial development. These latter skills orientations are inseparable instruments, which must exist to enable technological policy intervention to be effective. $\varepsilon$ and $\ddot{v}$ are white noise error terms assumed to be normally and independently distributed with the intervention instrument variables. The model represents a quantitative hypothetical representation which states that an entrepreneurial development policy is more likely to be successful in the presence of an ample injection of technological support, provided there is ethics in business and transparency in the allocation, use and management of resources on the part of business and government.

$\delta \mathrm{Y}_{\mathrm{m}} / \delta \mathrm{X}_{\mathrm{i}}>\delta \mathrm{Y}_{\mathrm{m}} / \delta \mathrm{X}_{\mathrm{a}}$ for all $\mathrm{X}_{\mathrm{i}}, \mathrm{X}_{\mathrm{a}} \mathrm{X}_{\mathrm{j}}=1$, and zero otherwise

Equation (3) assumes that the value of an entrepreneurial development initiative, however measured, is bound to be greater with an injection of technological orientation than without, provided there is an adequate management skills and orientation, including an awareness of ethics in business and transparency in government.

\section{HOW DO WE GET THE MOST OUT OF TECHNOLOGICAL ORIENTATION?}

What is fundamental in these proposals is not only technological orientation. We emphasize technological orientation, which forms an integral part of the spectrum of management education. Equally important is psychological reengineering. We need psychological re-orientation to accommodate transparency, persistence and a new mindset that accepts and fully embraces business ethics on the part of business owners. We need a new mindset on the part of government that must move away from double standard and espouse common standard and level playing field for every stakeholder. The machinery of government must be available to all in the use of enabling innovations and interventions and in making sure that appropriate punishment is given to all offending members of the business community. Government policy must not only be properly explained and publicized, it must also be sustained over a period long enough for results to be evaluated and assessed.

The new government policy of entrepreneurial development, which emphasizes bank funding and part ownership is suspect. There is no question that banks have the right to be concerned with the best use of the money they lend to small and medium-sized enterprises most of which have little or no collateral. The banks have equal right to be concerned with what the businesses do with the money they lend, but being part owner alone does not settle their concern, unless they get deeply involved in the day-to-day use of such money. This they cannot do, unless they are willing to direct their focus away from their traditional function of banking to management of businesses. Whether or not the banks are part owners of the businesses to which they lend money, the oversight function, which must include counseling, monitoring and progress reporting, must and should be undertaken by independent consultants. These consultants should be groups of individuals versed in all and related aspects of management education. We propose that Entrepreneurial Development Centers in the Schools of Business in local Universities be made to play that role. The local Universities should equip themselves to be able to play such roles by first equipping themselves with the relevant technology to train their students many of whom are expected to form the corps of future entrepreneurs.

Nigeria is a country with a long history of active government participation in the national economic affairs. For many years government-owned enterprises have served as the major sources of employment. For this reason, many Nigerian are still very skeptical about government divestiture. Similarly government assistance to the private sector has been implemented with very little zeal. Once assistance is given, there has always been very little government oversight policy to monitor performance. Giving no assistance is as bad as a haphazard policy in which assistance is given without a commitment to ensure success. What is needed is a private-government partnership in 
which any intervention policy is followed by a sustained monitoring policy to ensure that the assistance given by either a funding agency or government produces the desire results. Just as the banks need not be part owners of the enterprises to which they give loans, government need not be part owner of the enterprises, which they give any forms of assistance. Being part owners of any enterprise by funding agencies by itself does not guarantee such oversight functions, independent consultants such as the local Universities, on the contrary are equipped to provide these.

\section{CONCLUSION}

A case for integrating technology and modern management techniques has been made in this paper. Although this is not an empirical analysis, a persuasive case has been made in support of a case to incorporate simple technological innovations into the Nigerian small and medium-sized enterprises. The benefits identified in other developing countries are many and should surely be realized in Nigeria, provided all the applicable laws relating to transparency in governance and business are strictly enforced. There is abundant evidence in the literature to show that these benefits have been reported in other developing countries. The Nigerian economy of the $21^{\text {st }}$ Century should be allowed to benefit from easy access to the global market place through Internet web site procurement and advertising. They help to reduce cost and speed up production. It would also stand to benefit from the use of supply chain management and other forms of technologies, such as accounting, marketing and other data handling technologies. These simple forms of technology can easily be adapted into every-day use, not only by the medium, but small-sized enterprises that employ 20 persons or less.

\section{REFERENCES}

1. Chopra, Sunil and Peter Meindl, (2003): Supply Chain Management: Strategy, Planning and Operation. Prentice Hall.

2. Bhalla, Ajit S. and Dilmus D. James, (1991). Integrating New Technologies with Traditional Economic Activities in Developing Countries: An Evaluative Look at Technology Blending, Journal of Development Areas, Volume $24 \mathrm{~m}$, July.

3. Dahlman, Carl J. and Larry E. Westphal (1981). Meaning of Technological Mastry In Relation to the Transfer of Technology Annals of the American Academy of Political and Social Sciences, Volume 458, November.

4. Ekanem, Nkanta Frank, (2004). A Binary Choice Model for Optimum Entrepreneurial Development in An Economy Facing Environmental Constraints: International Business and Economics Research Journal, Volume 3, No. 11.

5. _ (2005). Methodology for Developing and Testing the Effectiveness of Using Entrepreneurial Skills and Supply-Side Innovations to Improve the Performance of Small and Medium-Sized Enterprises (Unpublished Manuscript).

6. Evans, David S. and Boyan Jovanovic (1989). An Estimated Model of Entrepreneurial Choice Under Liquity Constraints, Journal of Political Economy, 97(4), 808-826.

7. Kohler, Holm-Detlev (2002). What happens to Successful Cooperatives in Capitalist Globalization? www.geo.coop/Mondragon.htm.

8. Rustagi, Narendra K. (2001). International Technology Transfer: A Complement to Economic Restructuring, International Journal of Technology Management, Volume 21, No 5/6. 